\title{
Retrospective Study of Body Weight in Patients with Multiple Myeloma through Different Stages of the Disease
}

Authors

Affiliation
G. Talamo, J. Zhu, N. G. Dolloff, N. E. Lamparella, M. Joshi, A. Barochia, J. J. Drabick, J. Malysz

Milton S. Hershey Medical Center, Hershey, PA, USA

Key words
body weight
obesity
overweight
cachexia
multiple myeloma
stem cell transplant

received 24.03.2013

accepted 01.11.2013

\section{Bibliography}

DOI http://dx.doi.org/

10.1055/s-0033-1358760

Published online:

December 16, 2013

Metab Nutr Oncol 2013;

1: e7-e11 C Georg Thieme

Verlag KG Stuttgart · New York

eISSN 2194-735X

Correspondence

G. Talamo, MD

Penn State Hershey Cancer Institute

500 University Drive

Hershey, PA 17033

USA

Tel.: + 1/717/5318 678

Fax: + 1/717/5311 656

gtalamo@hmc.psu.edu

\section{License terms}

\section{Abstract}

$\nabla$

Background: Little is known regarding body weight changes in patients with multiple myeloma (MM) during the course of their disease, and the influence of obesity in the overall survival (OS) of patients affected by this cancer.

Methods: We retrospectively collected clinical data from $318 \mathrm{MM}$ patients, and analyzed their weight and body mass index (BMI) at various points throughout the course of the disease, including baseline, pre- and post-peripheral blood stem cell transplant (PBSCT), and time of death.

Results: At the time of diagnosis, median BMI was 28.1 ( \pm 5.7 SD; range, 15.3-51.8). The majority of MM patients were either overweight or

\section{Introduction}

$\nabla$

Multiple myeloma (MM) is a rare cancer, because it represents $1 \%$ of all malignancies. Its annual incidence is approximately 5/100000 [1]. Little is known regarding the body weight status of $\mathrm{MM}$ patients both at diagnosis and during the course of the disease. In particular, it is unclear whether the current epidemic of obesity affects even MM patients, or, instead, they develop progressive weight loss and cachexia during the terminal phase of their disease.

Excess body weight is a well-known risk factor not only for diabetes mellitus and cardiovascular disease, but even for cancer [2,3]. In fact, epidemiological evidence indicates that approximately $20 \%$ of all cancers are related to excess body weight [4], including $20 \%$ of breast and colon cancer cases, and about $40 \%$ of kidney and endometrial cancer cases [5]. Biologic mechanisms underlying the association between excess weight and cancer have not been completely elucidated, but several processes have been involved, including the presence of a chronic proinflamma- obese, both at the time of initial diagnosis (80\%) and in the terminal phase of the disease (66\%). Only $5 \%$ of patients had malnutrition at the time of death. Median body weight was 81.5 and $79.4 \mathrm{~kg}$ before and 6 weeks after high-dose chemotherapy and PBSCT $(\mathrm{p}<0.001)$. Kaplan-Meier estimates of OS showed similar results between patients with normal weight and obese patients. Conclusions: The majority of MM patients, at least in our cohort of U.S. residents, are either overweight or obese. Despite the common notion that the terminal phase of cancer is associated with cachexia, most MM patients did not experience a significant and progressive weight loss. PBSCT was associated with a statistically significant but clinically negligible weight loss. Obesity did not seem to influence overall survival in MM. 
- a known growth factor of neoplastic plasma cells - by the adipocytes [9], or to adiponectine, a hormone regulating glucose metabolism and fatty acid oxidation levels $[10,11]$.

In this study, we evaluated the BMI of MM patients during the course of the disease, including baseline, after high-dose chemotherapy and peripheral blood stem cell transplantation (PBSCT), and at the time of death. We also retrospectively analyzed the influence of BMI in the survival outcomes of MM.

\section{Materials and Methods}

After approval from our Institutional Review Board, we identified and reviewed data of all patients with a diagnosis of MM followed at the Penn State Cancer Hershey Cancer Institute between January 2006 and December 2011. We included in our analysis only patients who were diagnosed and directly followed at our Institution, and excluded those seen for second opinion and on occasional basis, for which weight measurements on the day of diagnosis (defined as the day of first bone marrow biopsy) and follow-up were not available. Weight and height were not self-reported, but objectively measured, and routinely checked at each clinic appointment. Patients were weighted at different times of the day, with only a gown or "light" clothing. We used the body mass index (BMI) (weight in $\mathrm{kg} /$ height in $\mathrm{m}^{2}$ ) as the objective method of quantifying the body fat, and we categorized it according to the established WHO criteria:

Table 1 Baseline characteristics of 318 patients with multiple myeloma.

\begin{tabular}{|c|c|c|}
\hline & BMI $<30(n=201)$ & $\mathrm{BMI} \geq 30(n=117)$ \\
\hline \multicolumn{3}{|l|}{ Age at diagnosis } \\
\hline Median, years (range) & $60(21-89)$ & $60(42-88)$ \\
\hline Sex, Male & $114(57 \%)$ & $68(58 \%)$ \\
\hline \multicolumn{3}{|l|}{ Race } \\
\hline Caucasian & $185(92 \%)$ & $104(89 \%)$ \\
\hline African-American & $11(5 \%)$ & $11(8 \%)$ \\
\hline Other & $5(2 \%)$ & $2(2 \%)$ \\
\hline \multicolumn{3}{|l|}{ Paraprotein } \\
\hline $\lg G, \lg A$ & $142(71 \%)$ & $93(79 \%)$ \\
\hline $\begin{array}{l}\text { Kappa or lambda light } \\
\text { chain }\end{array}$ & $50(25 \%)$ & $18(15 \%)$ \\
\hline Nonsecretory/other & $9(4 \%)$ & $6(5 \%)$ \\
\hline \multicolumn{3}{|l|}{ ISS stage } \\
\hline 1 & $67 / 171(39 \%)$ & $40 / 99(40 \%)$ \\
\hline$\|$ & $44 / 171(26 \%)$ & $28 / 99(28 \%)$ \\
\hline III & $60 / 171(35 \%)$ & $31 / 99(31 \%)$ \\
\hline \multicolumn{3}{|l|}{ \% PCs in BM at diagnosis } \\
\hline Median $( \pm S D)$ & $42 \%( \pm 28 \%)$ & $40 \%( \pm 34 \%)$ \\
\hline High-risk cytogenetics ${ }^{1}$ & $31 / 153(20 \%)$ & $20 / 83(24 \%)$ \\
\hline \multicolumn{3}{|l|}{ Treatment } \\
\hline Corticosteroids & $183(91 \%)$ & $109(93 \%)$ \\
\hline Thalidomide & $60(29 \%)$ & $46(41 \%)$ \\
\hline Lenalidomide & $143(71 \%)$ & $90(77 \%)$ \\
\hline Bortezomib & $175(87 \%)$ & $97(83 \%)$ \\
\hline Carfilzomib & $8(4 \%)$ & $6(5 \%)$ \\
\hline PBSCT & $112(56 \%)$ & $76(65 \%)$ \\
\hline IV Bisphosphonates & $171(85 \%)$ & $97(83 \%)$ \\
\hline \multicolumn{3}{|c|}{$\begin{array}{l}\mathrm{BM}=\text { bone marrow; } \mathrm{PBSCT}=\text { peripheral blood stem cell transplant; } \mathrm{PC}=\text { plasma cell; } \\
\text { ISS = International Staging System; IV= intravenous. Percentages have been rounded } \\
\text { and may not total to } 100 \%\end{array}$} \\
\hline \multicolumn{3}{|c|}{$\begin{array}{l}{ }^{1} \text { Defined as: hypodiploidy/complex karyotype or chromosome } 13 \text { abnormalities at } \\
\text { metaphase cytogenetics, or translocations } t(4 ; 14), t(14 ; 16) \text {, or del(17p) at fluores- } \\
\text { cence in situ hybridization (FISH) }\end{array}$} \\
\hline
\end{tabular}

BMI < 18.5 = "underweight"; 18.5-24.9= "normal"; 25-29.9= "overweight"; $\geq 30$ = "obese" $[12,13]$.

Statistical analysis was conducted using Minitab 16 Statistical Software 2010 (Minitab, Inc., State College, PA). Changes of body weight over time were assessed by paired T-Test. The method of Kaplan and Meier was used to compute the survival curves and to estimate median survival. Overall survival (OS) was calculated from the time of MM diagnosis. The differences in survival curves were tested with the log-rank method. Values of $p<0.05$ were considered statistically significant.

\section{Results}

$\nabla$

- Table 1 shows the characteristics of 318 evaluable patients with MM. None of the disease characteristics were statistically different between the groups of obese and non-obese patients. At the time of diagnosis, the median weight and BMI of the whole group were $81.7 \mathrm{~kg}( \pm 19.8 \mathrm{SD})$ and 28.1 ( $\pm 5.7 \mathrm{SD}$; range, 15.3-51.8), respectively. Three patients (1\%) were underweight, 60 (19\%) had normal weight, 138 (43\%) were overweight, and 117 (37\%) were obese. Among the latter, class I, II, and III (morbid obesity) were found in 70 (22\%), 31 (10\%), and (5\%) of patients, respectively. A histogram representation of the BMI at baseline is shown in 0 Fig. 1a. After induction therapy, 188 (59\%) patients underwent PBSCT, either upfront, i.e., within 12 months from diagnosis (147 pts), or late, as a salvage strategy during the course of the disease (41 pts). PBSCT was of autologous type in 177 patients (94\%). Median weight was $81.5 \mathrm{~kg}$ $( \pm 18.7$ SD) and $79.4( \pm 18.2$ SD) on the day of PBSCT and 6 weeks
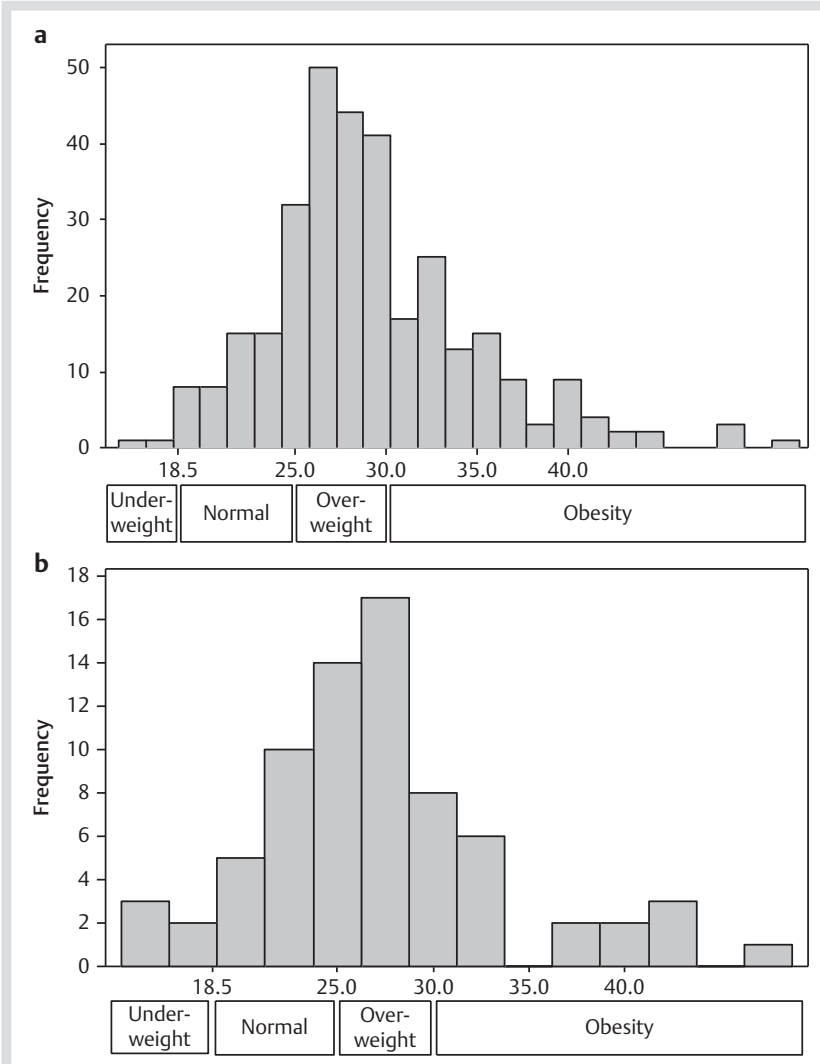

Fig. 1 Histogram of body mass index (BMI) in patients with multiple myeloma, at the time of diagnosis (318 patients) a, and within 4 weeks from the time of their death (73 patients) $\mathbf{b}$. 
later (at the time of post-transplant follow-up in the outpatient clinic) ( $\bullet$ Fig. 2a). This decrease of the median body weight by $2.1 \mathrm{~kg}$ was statistically significant ( $\mathrm{p}<0.001$ at paired $\mathrm{t}$ test). Among 182 evaluable patients, PBSCT was associated with a weight loss of $5-10 \%$ and $>10 \%$ in $56(31 \%)$ and $10(5 \%)$ patients, respectively. At the last database follow-up, 245 patients were alive and 73 dead. Among the latter, median body weight at diagnosis and within 4 weeks of death was 80.7 (SD 21) and 76.5 $($ SD 21) $\mathrm{kg}$, respectively $(\mathrm{p}=0.001)$ ( $\bullet$ Fig. $\mathbf{2 b}$ ), with a difference of $4.2 \mathrm{~kg}$ (95\% C.I, 1.83-6.62 kg). In a cohort of 73 living patients matched for time from diagnosis, median body weight was 85.5 $\mathrm{kg}(\mathrm{SD} 23)(\mathrm{p}=0.014)(\bullet$ Fig. $2 \mathrm{c})$, which represents a difference of $9.05 \mathrm{~kg}$ from the median in the cohort of dead patients $(95 \%$
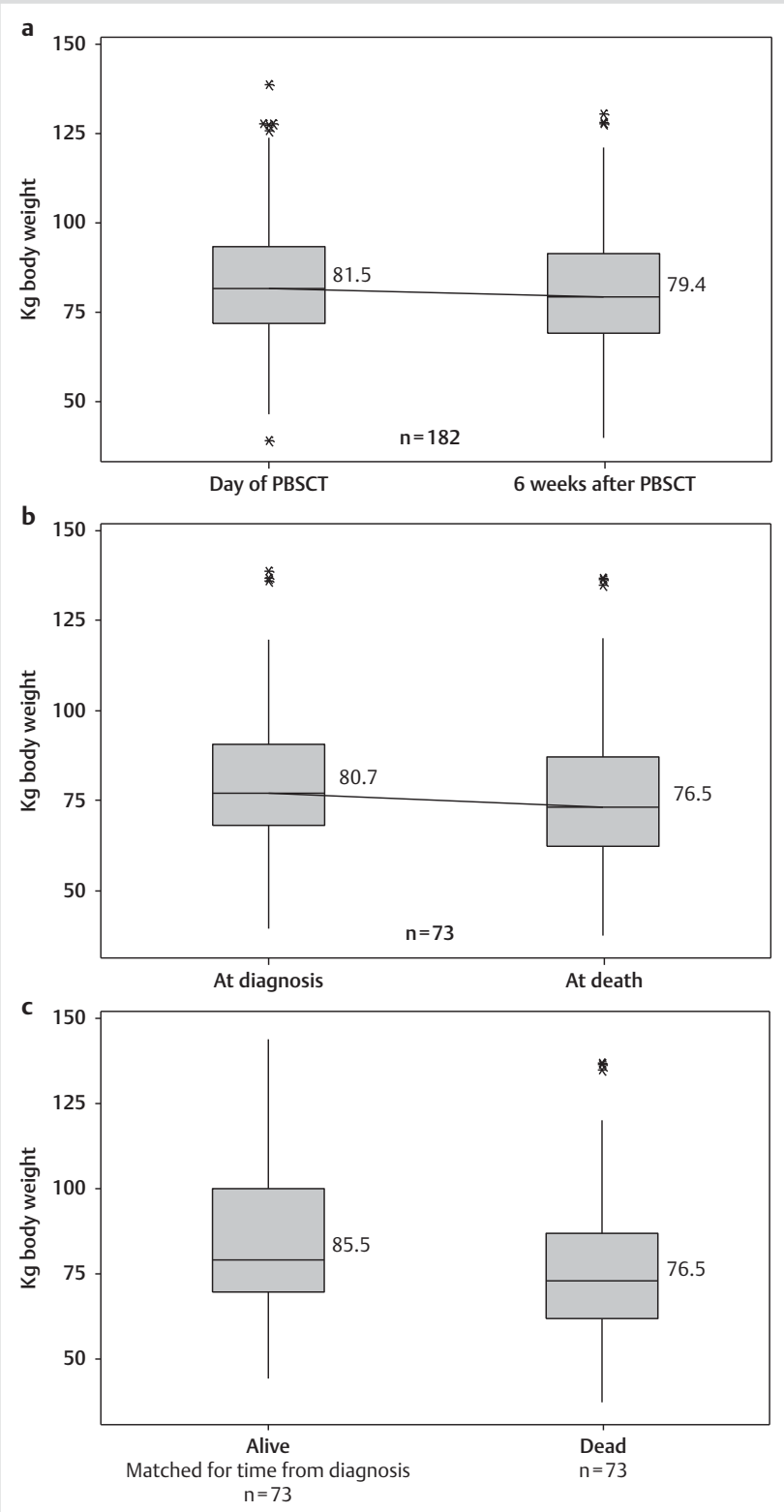

Fig. 2 Body weight $(\mathrm{Kg})$ in 182 myeloma patients who underwent autologous peripheral blood stem cell transplant (PBSCT), measured on the same day of PBSCT and 6 weeks after a; Body weight in 73 myeloma patients who died with relapsed/refractory disease, measured at the time of diagnosis (defined as the day of first bone marrow biopsy) and within the last 4 weeks of their life $\mathbf{b}$; Body weight of the same 73 dead patients compared to a cohort of other 73 myeloma patients matched for time from diagnosis $\mathbf{c}$.
C.I., $1.9-16.2 \mathrm{~kg})$. At the time of death, $4(5 \%)$ patients were underweight, 21 (29\%) had normal weight, and 48 (66\%) were either overweighted (30 pts) or obese (18 pts). Median BMI measured within 4 weeks of last follow-up was 28.1 ( $\pm 5.9 \mathrm{SD})$ and $26.5( \pm 6.4 \mathrm{SD}) \mathrm{kg}$ among alive and dead patients, respectively $(p=0.03)$. 0 Fig. $\mathbf{1 b}$ shows the histogram representation of the weight of MM patients within 4 weeks from the time of their death.

After a median follow-up of 28 months, median OS of the whole cohort of MM patients was not reached. Comparison of KaplanMeier estimates of both overall survival (OS) and progressionfree survival (PFS) in 117 patients with BMI at baseline < 30 vs. 201 patients with BMI 30 or higher (i.e., obese), did not find a statistically significant difference ( $p>0.05$ at log-rank test) ( $\odot$ Fig. 3). Proportional hazards regression, using age and ISS stage as baseline covariates, did not modify the above results.

\section{Discussion}

$\nabla$

Our study showed that the majority of patients with MM are overweight or obese, and they remain so even during the course of their disease. Although terminally ill cancer patients are traditionally believed to experience a phase of tissue wasting and cachexia $[14,15]$, our data show that the weight loss accompanying the terminal phase of MM is relatively small, and the majority of our patients dying of progressive and refractory MM had a BMI $>25 \mathrm{~kg} / \mathrm{m}^{2}$. Within 4 weeks of death, our MM patients has a median body weight loss of about $4.2 \mathrm{~kg}$ compared with their weight at diagnosis, and a difference of $9.05 \mathrm{~kg}$ when compared with the median weight of living patients matched for

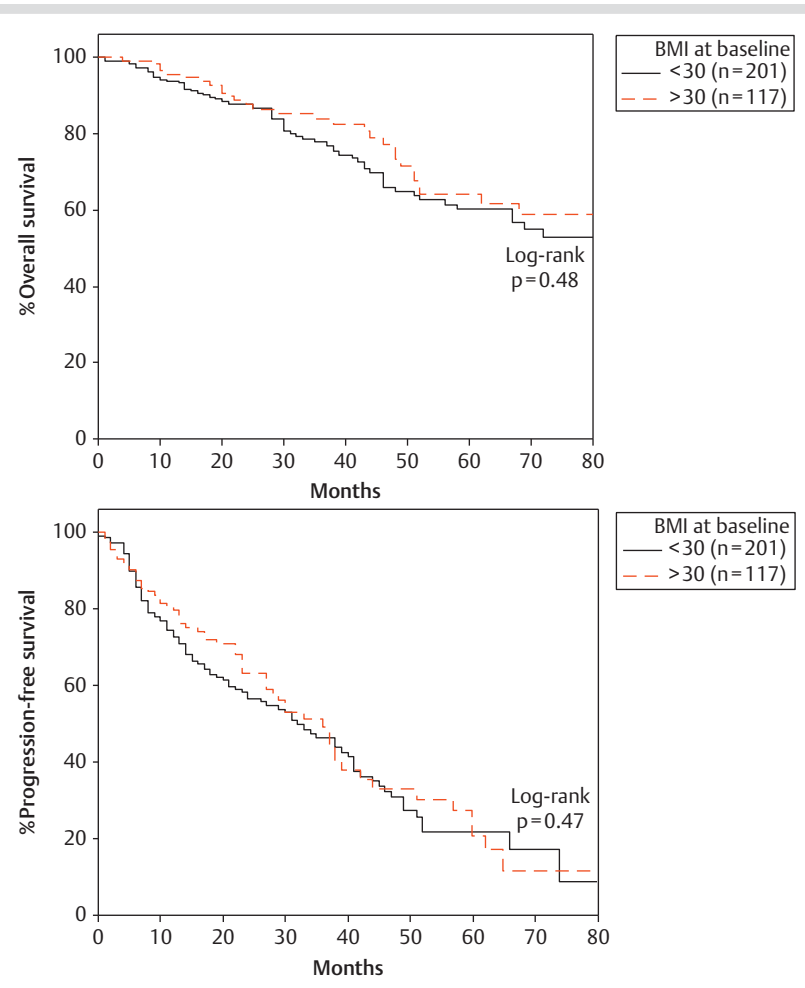

Fig. 3 Kaplan-Meier estimates of overall survival (OS) and progressionfree survival (PFS) in patients with multiple myeloma, according to their BMI at diagnosis. OS and PFS are calculated from the time of initial diagnosis. 
time of diagnosis. Despite these differences, only $5 \%$ of dying MM patients were underweight. Another surprising finding of our study is that high-dose chemotherapy and PBSCT were not associated with a significant weight loss. This is counterintuitive, because the immediate post-transplant period is usually associated with lack of appetite, nausea, vomiting, and oral mucositis, all factors that may prevent food intake and adequate nutrition. We speculate that PBSCT supportive care, with modern antiemetic regimens and total parenteral nutrition (TPN) in patients who are unable to ingest food, is mainly responsible for this weight stability. Our data showed that the median weight loss was about $2 \mathrm{~kg}$ over 6 weeks post-PBSCT. This was highly significant from the statistical point of view, but clinically insignificant, in our opinion.

Another finding of our study is that obesity is not associated with an inferior survival outcome in MM (but, obviously, limitation of our sample size could have precluded the detection of small differences in survival). Evidence for obesity affecting clinical outcomes in cancer is mixed: some studies reported that obesity adversely impacts on OS (e.g., breast cancer), whereas other studies found no effect (e.g., hematologic malignancies treated with allogeneic PBSCT) [4,16]. Theoretically, obesity could affect outcomes in various potential ways, for example by leading to altered pharmacokinetics of chemotherapeutic agents, or by erratic dosing of chemotherapy, due to variation in dose adjustment methods (e.g., calculating based on ideal body weight vs. adjusted body weight). Vogl et al. studied the effect of obesity on outcomes of MM undergoing autologous PBSCT, and found that obesity did not seem to significantly affect $O S$, a result that reflects our findings [17]. We do not know whether obesity is a relevant cofactor in affecting clinical outcomes in MM. However, we could not find significant differences in the use of novel agents and PBSCT between patients with normal BMI and those with BMI > 30 ( $\bullet$ Table 1 ), which, at least, suggests that obesity does not refrain oncologists from the successful use of modern and aggressive chemotherapies.

Limitations of our study include its retrospective nature and the lack of a control cohort. More importantly, it includes only U.S. residents, and therefore it cannot reflect the true body weight and BMI of MM patients in the rest of the world. In a recent study conducted in our geographical area, using data from 1342 adult women enrolled in the Central Pennsylvania Women's Health Study, $28 \%$ of the sample was classified as overweight, and $26 \%$ as obese [18]. These percentages are significantly lower than those shown in our MM patients, but we cannot make comparisons, even because those patients were all females, and data could be inaccurate, because weight was self-reported in that study. Other limitations are the lack of body weight data before the diagnosis of MM (making impossible to assess whether MM is associated with weight loss before its diagnosis), and data regarding the influence of corticosteroids on body weight. These drugs, known to potentially induce weight gain, are often used in the treatment of MM (in fact, $>90 \%$ of our patients received either prednisone or dexamethasone as part of their chemotherapy regimens). The strength of our study consists of reporting data of patients followed at various points throughout the course of the disease. Moreover, weight and height were objectively measured, whereas, in other studies, these data were selfreported [19-22]. This is a relevant aspect, as self-reported weights tend to underestimate the true BMI [23].
In conclusion, we found that most MM patients are overweight or obese, and they remain so during the various stages of the disease. Obesity did not appear to produce a negative impact on survival of MM patients. Our results were confined to US patients, and they may not be valid for all MM patients living in the rest of the world, but we should also acknowledge that the prevalence of obesity is progressively increasing worldwide.

\section{Conflict of Interest}

$\nabla$

None declared.

\section{References}

1 Siegel R, Ward E, Brawley O,Jemal A. Cancer statistics, 2011: the impact of eliminating socioeconomic and racial disparities on premature cancer deaths. CA Cancer J Clin 2011; 61: 212-236

2 Perez Perez A, Ybarra Munoz J, Blay Cortes V, de Pablos Velasco P. Obesity and cardiovascular disease. Public Health Nutr 2007; 10: 1156-1163

3 Renehan AG, Tyson M, Egger M, Heller RF, Zwahlen M. Body-mass index and incidence of cancer: a systematic review and meta-analysis of prospective observational studies. Lancet 2008; 371: 569-578

4 Wolin KY, Carson K, Colditz GA. Obesity and cancer. Oncologist 2010; 15: $556-565$

5 Calle EE, Kaaks R. Overweight, obesity and cancer: epidemiological evidence and proposed mechanisms. Nat Rev Cancer 2004; 4: 579-591

6 Wallin A, Larsson SC. Body mass index and risk of multiple myeloma: a meta-analysis of prospective studies. Eur J Cancer 2011; 47: 16061615

7 Larsson SC, Wolk A. Body mass index and risk of multiple myeloma: a meta-analysis. Int J Cancer 2007; 121: 2512-2516

8 Landgren O, Rajkumar SV, Pfeiffer RM, Kyle RA, Katzmann JA, Dispenzieri A, Cai Q, Goldin LR, Caporaso NE, Fraumeni JF, Blot WJ, Signorello LB. Obesity is associated with an increased risk of monoclonal gammopathy of undetermined significance among black and white women. Blood 2010; 116: 1056-1059

9 Mohamed-Ali V, Goodrick S, Rawesh A, Katz DR, Miles JM, Yudkin JS, Klein S, Coppack SW. Subcutaneous adipose tissue releases interleukin-6, but not tumor necrosis factor-alpha, in vivo. J Clin Endocrinol Metab 1997; 82: 4196-4200

10 Reseland JE, Reppe S, Olstad OK, Hjorth-Hansen H, Brenne AT, Syversen $U$, Waage A, Iversen PO. Abnormal adipokine levels and leptin-induced changes in gene expression profiles in multiple myeloma. Eur J Haematol 2009; 83: 460-470

11 Hofmann JN, Liao LM, Pollak MN, Wang Y, Pfeiffer RM, Baris D, Andreotti $G$, Lan $Q$, Landgren 0 , Rothman N, Purdue MP. A prospective study of circulating adipokine levels and risk of multiple myeloma. Blood 2012; 120: 4418-4420

12 Use and interpretation of anthropometric indicators of nutritional status. WHO Working Group. Bull World Health Organ 1986; 64: 929-941

13 Physical status: the use and interpretation of anthropometry. Report of a WHO Expert Committee. World Health Organ Tech Rep Ser 1995; 854: $1-452$

14 Norton JA, Peacock JL, Morrison SD. Cancer cachexia. Crit Rev Oncol Hematol 1987; 7: 289-327

15 Fearon K, Strasser F, Anker SD, Bosaeus I, Bruera E, Fainsinger RL, Jatoi A, Loprinzi C, MacDonald N, Mantovani G, Davis M, Muscaritoli M, Ottery F, Radbruch L, Ravasco P, Walsh D, Wilcock A, Kaasa S, Baracos $V E$. Definition and classification of cancer cachexia: an international consensus. Lancet Oncol 2011; 12: 489-495

16 Nikolousis E, Nagra S, Paneesha S, Delgado J, Holder K, Bratby L, Chaganti $S$, Lovell R, Milligan D. Allogeneic transplant outcomes are not affected by body mass index (BMI) in patients with haematological malignancies. Ann Hematol 2010; 89: 1141-1145

17 Vogl DT, Wang T, Perez WS, Stadtmauer EA, Heitjan DF, Lazarus HM, Kyle RA, Kamble R, Weisdorf D, Roy V, Gibson J, Ballen K, Holmberg $L$, Bashey A, McCarthy PL, Freytes C, Maharaj D, Maiolino A, Vesole D, Hari $P$. Effect of obesity on outcomes after autologous hematopoietic stem cell transplantation for multiple myeloma. Biol Blood Marrow Transplant 2011; 17: 1765-1774 
18 Kraschnewski JL, McCall-Hosenfeld JS, Weisman CS. Prospective association between body mass index and receipt of preventive services: results from the Central Pennsylvania Women's Health Study (CePAWHS). Prev Med 2012; 54: 302-305

19 Patel AV, Diver WR, Teras LR, Birmann BM, Gapstur SM. Body mass index, height, and risk of lymphoid neoplasms in a large US cohort. Leuk Lymphoma 2013; 54: 1221-1227

20 Blair CK, Cerhan JR, Folsom AR, Ross JA. Anthropometric characteristics and risk of multiple myeloma. Epidemiology 2005; 16: 691-694

21 Birmann BM, Giovannucci E, Rosner B, Anderson KC, Colditz GA. Body mass index, physical activity, and risk of multiple myeloma. Cancer Epidemiol Biomarkers Prev 2007; 16: 1474-1478
22 Fernberg P, Odenbro A, Bellocco R, Boffetta P, Pawitan Y, Zendehdel K, Adami J. Tobacco use, body mass index, and the risk of leukemia and multiple myeloma: a nationwide cohort study in Sweden. Cancer Res 2007; 67: 5983-5986

23 Kuczmarski MF, Kuczmarski RJ, Najjar M. Effects of age on validity of self-reported height, weight, and body mass index: findings from the Third National Health and Nutrition Examination Survey, 1988-1994. J Am Diet Assoc 2001; 101: 28-34 